\title{
A APA DA BALEIA FRANCA E O TURISMO DE OBSERVAÇÃO DE BALEIAS EMBARCADO (TOBE): SUSTENTABILIDADE OU EXPLORAÇÃO ANIMAL?
}

\section{L'APABF ET LE TOURISME DE OBSERVATION DE BALEINE: DÉVELOPPEMNT DURABLE OU EXPLOITATION ANIMAL?}

\author{
${ }^{1}$ Fernanda Luiza Fontoura de Medeiros \\ ${ }^{2}$ Letícia Albuquerque
}

\section{RESUMO}

O Sistema Nacional de Unidades de Conservação, regulado pela Lei 9985/2000, estabelece duas grandes categorias de Unidades de Conservação: as unidades de conservação de proteção integral e as unidades de conservação de uso sustentável. Entre as unidades de conservação de uso sustentável, as áreas de proteção ambiental caracterizam-se por serem áreas extensas, instituídas para a preservação dos processos naturais e da biodiversidade, bem como para regular as atividades humanas às características ambientais da área. Assim, no sul do estado de Santa Catarina foi instituída a Área de Proteção Ambiental da Baleia Franca (APABF), com o objetivo principal de proteger nas aguas brasileiras a baleia franca austral. Recentemente, a APABF esta sendo palco de um intenso conflito socioambiental em razão da Ação Civil Pública (ACP) interposta pelo Instituto Sea Shepherd Brasil em face do Instituto Chico Mendes da Biodiversidade (ICMBIO), pedindo a condenação do ICMBIO a adotar de forma permanente, as medidas necessárias e eficazes para a proteção das baleias-francas, mediante a fiscalização das empresas que praticam a observação das baleias com uso de embarcações, com ou sem motor, a fim de impedir a violação da legislação. Este artigo consiste em um estudo de caso e visa contribuir para o conhecimento do caso do turismo de observação de baleias embarcado na APABF, através da analise da legislação aplicada, como dos atores envolvidos na controvérsia judicial e o seu reflexo para os direitos animais. A pesquisa é feita através da analise documental da legislação que caracteriza as unidades de conservação, da legislação especifica de proteção aos cetáceos, bem como dos argumentos utilizados pelas partes envolvidas na ACP.

Palavras-chave: Direito dos animais, Ação civil pública, Unidades de conservação

\footnotetext{
${ }^{1}$ Doutora em Direito pela Universidade Federal de Santa Catarina - UFSC, Florianópolis - SC (Brasil). Professora da Pontifícia Universidade Católica do Rio Grande do Sul - PUCRS, Porto Alegre - RS (Brasil).

E-mail: flfmedeiros@gmail.com

${ }^{2}$ Doutora em Direito pela Universidade Federal de Santa Catarina - UFSC, Florianópolis - SC (Brasil). Professora da Universidade Federal de Santa Catarina - UFSC, Florianópolis - SC (Brasil).

E-mail: let_albuquerque@yahoo.com.br
} 


\section{RÉSUMÉ}

Le Système national d'unités de conservation, réglementé par la loi 9985/2000 établit deux grandes catégories de zones protégées: las zones protégées de protection intégrale et des zones protégées de usage durables. Les zones protégées de usage durable sont caractérisées par de vastes zones et sont institué pour la préservation des processus naturels et de la biodiversité, ainsi que pour réglementer les activités humaines aux caractéristiques environnementales de la région. Ainsi, à Santa Catarina a été établi l'Aire de Protection Environnementale de la Baleine Franche (APABF), leur objectif principal être de proteger dans les eaux brésiliennes la baleine franche australe. Récemment, cette APABF est sûr la scène d'un intenses conflits sociaux et environnementaux en raison de une mesure juridique déposée par l'Institut Sea Shepherd Brésil vers l'Institut Chico Mendes pour la biodiversité (ICMBio), pour obtenir une ordonnance de ICMBio à adopter de façon permanente, les mesures nécessaires et efficaces pour la protection des baleines, par le contrôle des entreprises qui effectuent le tourisme de observation des baleines avec l'utilisation de bateaux avec ou sans moteur, afin d'éviter une violation de la législation. Cet article consiste en une étude de cas et à pour objectif contribuer à la connaissance du cas de l'observation des baleines avec bateau a $\mathrm{APABF}$ à travers l'analyse de la législation appliquée, tels que les acteurs impliqués dans la controverse juridique et son reflet pour les droits des animaux. L'enquête est menée par l'analyse documentaire du droit qui caractérise les zones protégées, la législation spécifique pour la protection des cétacés, ainsi que les arguments utilisés par les parties concernées dans laffaire juridique.

Mots-clés: Droits des animaux, Action civile, Zones protégées 


\section{INTRODUÇÃO}

O tema central proposto por esse pequeno ensaio é a inter-relação entre o animal humano e o animal não humano em uma sociedade cuja a prática da exploração do ambiente, de forma inconsequente e irresponsável, é uma constante. A questão central consiste na análise da utilização, alegadamente, sustentável do turismo de observação de baleia embarcado - TOBE - em área de preservação ambiental.

O presente artigo pretende verificar se o modelo de desenvolvimento econômico implementado na área da APA tem como base o que prega o Sistema Nacional de Unidades de Conservação - um modelo baseado na sustentabilidade - ou se a lógica dominante continua centrada na exploração dos recursos ambientais sem considerar os parâmetros de proteção ambiental. O caso envolvendo a proibição do TOBE na região da APA será utilizado para ilustrar tal situação. A escolha justifica-se em razão desse caso ser um microcosmo que reflete a nossa realidade, ou seja, por meio da análise dos atores envolvidos e das ações engendradas a partir dos fatos apresentados é possível verificar qual é o papel do Judiciário, do Ministério Público, da sociedade civil e do poder público em lidar com tal questão. O objetivo é demonstrar que há um investimento no risco, contrariando o princípio de precaução, bem como demonstrar a contradição entre proteção ambiental em áreas de relevante interesse ecológico, como é o caso da APA, e o desenvolvimento de atividades econômicas danosas, como é o caso do TOBE. A metodologia de pesquisa aplicada a esse estudo parte de uma análise documental crítica-reflexiva, legislativa e doutrinária, assim como utiliza de levantamento de dados colhidos no Poder Judiciário.

Vivemos em um período de intensos contrastes, seja de desenvolvimento econômico, social ou ambiental. Vivemos um planeta em que a desconexão com o ambiente natural se tornou regra e não exceção. Tal postura tem instigado a elaboração de textos de lei que busquem forçar um comportamento protetivo, se é que esse é um recurso eficaz. Ao mesmo tempo em que a economia mundial aprimora-se para além do industrial e a sociedade deslumbra-se com as habilidades de nossa civilização para as grandiosas descobertas técnico-científicas, paradoxalmente nos distanciamos, cada vez mais, da intimidade com o planeta onde vivemos.

Esta realidade impactante enseja um questionamento profundo acerca da maneira como a humanidade tem direcionado sua relação com o meio ambiente. A 
visão holística e sistêmica ${ }^{1}$ do homem interagindo com o mundo e do mundo interagindo com o homem tem invadido nossas produções científicas e acadêmicas. Estudos deste tema nas mais diversas áreas do conhecimento remetem-nos à dimensão de transdisciplinaridade ${ }^{2}$ e interdisciplinaridade ${ }^{3}$, pois a preocupação com o ambiente alcança ramos do conhecimento muito além das ciências jurídicas. Contudo, em que pese as dimensões extrajurídicas, é na perspectiva jurídica que se assenta o presente artigo, sem renunciar à eventuais incursões em outras searas, como já tivemos oportunidade de defender (MEDEIROS, 2004).

Nossa civilização luta incessantemente para gerar e comercializar riquezas. Na luta por estes objetivos, imergimos em um ambiente em constante desintegração dos recursos naturais e do próprio humano, correndo o risco de gerar um mundo artificial ${ }^{4}$. Nossas ações e omissões referentes ao meio ambiente estão destruindo o planeta, colocando em risco a existência da própria civilização. Embora o contraste entre nossa civilização e a dos nossos ancestrais seja marcante, temos na realidade algo em comum: dependemos também, totalmente, dos sistemas e recursos naturais da Terra para o nosso sustento. Infelizmente, a expansão da economia global, na forma em que está estruturada, tem subjugado nossos ecossistemas. Isto pode ser comprovado diante das inúmeras questões ambientais globais emergentes, tais como o desaparecimento de espécies vegetais e animais, o encolhimento das florestas, o aquecimento da temperatura do planeta, a erosão dos solos, a produção avassaladora de lixo doméstico e tóxico, a poluição e a escassez da água, a extinção da própria espécie humana em sua

face econômica perversa.

\footnotetext{
1 Entende-se como “condição holística e sistêmica”, segundo autores como Fritoj Capra e Maturana e Varela, respectivamente nas obras 1997 e 1995, as propostas de exame da realidade e da interação entre os agentes envolvidos que contemplam o todo e as partes, assim como a visão local com perspectiva do universal, do global.

$2 \mathrm{O}$ conceito de transdisciplinaridade, segundo Japiassu in G. Rohde, Op. Cit., p.86, é a “coordenação de todas as disciplinas e interdisciplinas do sistema de ensino inovado sobre a base de uma axiomática geral, representando um sistema de níveis e objetivos múltiplos: coordenação com vistas a uma finalidade comum dos sistemas”. Desta feita, observamos que as relações ambientais expressam ações não relacionadas estritamente a uma só disciplina. Pela própria natureza da área, indicam processos, no mínimo, interdisciplinares.

3 Conforme o entendimento de Hilton Japiassu in G. Rohde, Epistemologia Ambiental, p.86. O conceito de interdisciplinaridade pode traduzir-se pela "axiomática comum a um grupo de disciplinas conexas e definida no nível hierárquico imediatamente superior, o que introduz a noção de finalidade, especificado por um sistema de dois níveis e de objetivos múltiplos: coordenação procedendo do nível superior".

4 Quando nos referimos à geração de um mundo artificial fazemos alusão a um mundo com uma natureza não-natural, com o ar poluído, as florestas desaparecidas, a miséria social e econômica se ampliando e dominando as propostas contra hegemônicas a este mundo.
} 
O papel da ciência jurídica, atualmente, atinge patamares mais elevados, pois a complexidade da sociedade moderna exige a regulamentação de novas situações, antes inexistentes no mundo jurídico, como requisito cogente ao ordenamento social. Neste contexto, podemos citar as relações do homem com o meio ambiente, cujos fatos obrigam o reconhecimento de novos bens e posições jurídicas, entre elas o relacionamento ambienteanimal humano-animal não humano.

\section{ESPAÇOS TERRITORIAIS ESPECIALMENTE PROTEGIDOS}

A Constituição Federal de 1988 estabeleceu a incumbência de criar espaços ambientais, especialmente protegidos em razão de sua relevância ecológica, ao poder público, conforme dispõe o inciso III, do $§ 1^{\circ}$, do artigo 225.

Art. 225. Todos têm direito ao meio ambiente ecologicamente equilibrado, bem de uso comum do povo e essencial à sadia qualidade de vida, impondo- se ao Poder Público e à coletividade o dever de defendê-lo e preservá-lo para as presentes e futuras gerações.

\$ $1^{\circ}$ Para assegurar a efetividade desse direito, incumbe ao Poder Público: III definir, em todas as unidades da Federação, espaços territoriais e seus componentes a serem especialmente protegidos, sendo a alteração e a supressão permitidas somente através de lei, vedada qualquer utilização que comprometa a integridade dos atributos que justifiquem sua proteção (grifo nosso).

A Constituição Federal, portanto, determinou que áreas territoriais ambientalmente importantes no país fossem protegidas de forma especial. Durante um longo período de tempo a norma constitucional não foi regulamentada e o sistema jurídico brasileiro estabelecia as regras de proteção dessas áreas especiais, exclusivamente através de Resoluções do Conselho do Meio Ambiente (CONAMA).

\subsection{O Sistema Nacional das Unidades de Conservação}

Historicamente, a preocupação em criar espaços protegidos em razão da sua relevância ecológica remonta a criação, no século XIX, dos jardins botânicos, como por exemplo, o Jardim Botânico do Rio de Janeiro, criado em 1811, e tantos outros que o seguiram. No entanto, é a partir da década de 1930, com a instituição de vários parques nacionais (seguindo o modelo norte-americano), é que se vê um avanço nessa área. Nesse 
período foram criados espaços importantes de proteção, como o Parque Nacional de Itatiaia, o Parque Nacional de Iguaçu e o Parque Nacional da Serra dos Órgãos ${ }^{5}$. Como salienta Milano (1999, p.2), o conjunto de unidades de conservação no Brasil é um "sistema" não representativo e significativo perante a diversidade de objetivos de conservação a ele atribuída, devido ao processo de colonização ou ocupação territorial, bem como do processo da política de conservação de recursos naturais brasileiros.

Em 2000, finalmente, foi publicada a Lei n. 9.985, conhecida como a Lei do SNUC (Sistema Nacional das Unidades de Conservação) que veio a normatizar (regulamentando o inciso III, do parágrafo 1, do art. 225 da CFRB) e a sistematizar as unidades de Conservação no Brasil que, até o momento, eram reguladas por meio de Resoluções esparsas emanadas do CONAMA.

Dessa forma, entre esses espaços especialmente protegidos encontram-se as unidades de conservação, regulamentadas pela Lei n. ${ }^{\circ}$ 9.985/2000, que estabeleceu o Sistema Nacional de Unidades de Conservação - SNUC. As unidades de conservação consistem em espaços ambientais especialmente protegidos, não só em razão da sua relevância ecológica, mas, sobretudo, por representarem um novo modelo de desenvolvimento e utilização dos recursos ambientais.

Segundo o SNUC, as unidades de conservação, integrantes do sistema, dividem- se em dois grupos com características bem específicas e distintas uma das outras: Unidades de Proteção Integral e Unidades de Uso Sustentável. As unidades catalogadas como de proteção integral são caracterizadas como um espaço territorial voltado a "manutenção dos ecossistemas livres de alterações causadas por interferência humana, admitindo apenas o uso indireto dos seus atributos naturais" (art. $2^{\circ}$, inciso VI, da Lei n. ${ }^{\circ}$ 9.985/00). Já as unidades de conservação de uso sustentável, são aquelas que admitem certa "exploração do ambiente de maneira a garantir a perenidade dos recursos ambientais renováveis e dos processos ecológicos, mantendo a biodiversidade e os demais atributos ecológicos, de forma socialmente justa e economicamente viável" (art.

$2^{\circ}$, inciso XI, da Lei n. 9.985/00).

\footnotetext{
${ }^{5}$ Instituídos, respectivamente, pelos seguintes Decretos: Decreto 1713/37; Decreto-lei 1035/39; Decreto-lei 1822/39).
} 
O grupo das Unidades de Proteção Integral é composto por cinco categorias de unidades de conservação: Estação Ecológica; Reserva Biológica; Parque Nacional; Monumento Natural e Refúgio da Vida Silvestre. O grupo das Unidades de Usos Sustentável é constituído por sete categorias de unidades de conservação: Área de Proteção Ambiental; Área de Relevante Interesse Ecológico; Floresta Nacional; Reserva Extrativista; Reserva da Fauna; Reserva do Desenvolvimento Sustentável e Reserva Particular do Patrimônio Natural.

É importante frisar que o conceito constitucional de espaços ambientalmente protegidos abrange, além das Unidades de Conservação, as áreas de preservação permanente, as reservas legais, os biomas constitucionalmente protegidos (Floresta Amazônica, Mata Atlântica, Serra do Mar, Pantanal Mato-grossense e a zona costeira) e as reservas da biosfera. Assim, espaço territorial especialmente protegido é um conceito amplo e genérico que engloba as Unidades de Conservação. Contudo, como frisa José Afonso da Silva, nem sempre diante da legislação vigente é possível determinar quando um espaço territorial especialmente protegido deve ser considerado Unidade de Conservação. Para o autor (SILVA, 2004, p.232), o máximo que podemos afirmar é que um espaço territorial se torna uma Unidade de Conservação quando assim é declarado de forma expressa, para lhe atribuir um regime jurídico mais restritivo e mais determinado.

\subsection{As áreas de proteção ambiental}

Dentre as unidades de conservação estabelecidas pela legislação federal brasileira, a que nos ocupa a reflexão, nesse momento é a Área de Proteção Ambiental, unidade de conservação de uso sustentável, comumente denominada como APA. Com o escopo de estabelecer um paradigma conceitual para a fala, partimos da concepção legal de alguns conceitos relevantes para a compreensão do tema. O primeiro deles é acerca do significado de uso sustentável e o segundo, o entendimento de APA. O significado de uso sustentável já apresentamos no item anterior, passamos, agora, a nos ater ao entendimento de APA.

A partir do conceito de uma Unidade de Conservação da categoria de Usos Sustentável, estabelecida em lei, se tem que não há nenhum impedimento à exploração do ambiente, desde que não se coloque em risco a perenidade dos recursos ambientais renováveis, mantendo a biodiversidade do local. A exploração apenas será incompatível com uma unidade de conservação, caso coloque a sua função ambiental em 
risco. A Área de Proteção Ambiental - APA - é uma unidade de conservação de uso sustentável, ou seja, a Lei do SNUC permite que utilização dos recursos naturais do espaço, desde que não coloque em risco a própria finalidade da APA.

Segundo a Lei do SNUC, temos que APA (art. 15 da Lei n. ${ }^{\circ}$ 9.985/00) é uma área de proteção

[...] em geral extensa, com um certo grau de ocupação humana, dotada de atributos abióticos, bióticos, estéticos ou culturais especialmente importantes para a qualidade de vida e o bem-estar das populações humanas, e tem como objetivos básicos proteger a diversidade biológica, disciplinar o processo de ocupação e assegurar a sustentabilidade do uso dos recursos naturais (grifo nosso)

Apesar da Lei do SNUC fazer referência "a um certo grau de ocupação humana" as áreas de proteção ambiental são áreas extremamente extensas e que, por vezes, englobam municípios inteiros, o que nos leva a poder afirmar que possui áreas públicas e privadas e ambas sofrem limitações ao exercício do direito de propriedade.

Toda a unidade de conservação deve apresentar um plano de manejo. Conforme a Lei do SNUC, plano de manejo é:

documento técnico mediante o qual, com fundamento nos objetivos gerais de uma unidade de conservação, se estabelece o seu zoneamento e as normas que devem presidir o uso da área e o manejo dos recursos naturais, inclusive a implantação das estruturas físicas necessárias à gestão da unidade

Sem exceção, as unidades de conservação devem dispor de um Plano de Manejo e este plano deve ser elaborado em um prazo de 5 (cinco) anos, a partir da criação da unidade de conservação. Machado (2012, p. 956) sustenta, com maestria, que "passado esse prazo, os órgãos executores (ICMBio, por exemplo) podem figurar como réus em uma Ação Civil Pública".

Os objetivos do SNUC estão bem especificados na legislação e, entre eles destacamos: 1) o dever de contribuir para a manutenção da diversidade biológica e dos recursos genéticos no território nacional e nas águas jurisdicionais; 2) proteger as espécies ameaçadas de extinção no âmbito regional e nacional; e, 3) contribuir para a preservação e a restauração da diversidade de ecossistemas naturais. Dessa feita, há de se ter cuidado com a utilização dos espaços protegidos e as regras de utilização estabelecidas nos planos de manejo das unidades de conservação. Em razão disso que se aplica ao plano de manejo os princípios da precaução e da prevenção. 
Cabral e Souza $(2005$, p.47) ressaltam que a categoria APA é singular, pois não há qualquer tipo ou categoria em outros países que se iguale aos objetivos de criação de uma APA, uma vez que esta é uma unidade de uso sustentável e que pode ser instituída em terras públicas ou privadas (geralmente ambas coexistem), criada pelo poder público (com a participação da sociedade civil), manejada pelos proprietários desde que obedeçam a medidas restritivas impostas pelo poder público no sentido de garantir a conservação dos atributos que motivaram a sua criação e gerenciada por meio do Conselho Gestor que pode (e deve) funcionar como fórum de debates para equacionar os conflitos da região.

Cerca de 3,9\% do território nacional está sob proteção na forma de Unidades de Conservação. Com base em dados fornecidos pelo IBAMA, existem 48 dessas áreas distribuídas pela zona costeira. No que tange a zona costeira, o desafio maior é proteger e garantir as múltiplas funções dos seus recursos com a finalidade de compatibilizar o uso e a ocupação desse território. O Plano Nacional de Gerenciamento Costeiro, instituído pela Lei 7661/81, estabelece em seu artigo $9^{\circ}$ que para evitar a degradação ou o uso indevido dos ecossistemas, do patrimônio e dos recursos naturais da zona costeira, o PNGC poderá prever a criação de unidades de conservação permanente, de acordo com a legislação vigente.

A quase totalidade dessas áreas de preservação está protegida por decretos federais, sancionados principalmente na década de 80, como é o caso da Reserva Biológica do Arvoredo, situada em SC. Apesar de uma legislação favorável à preservação das espécies e de seus habitats, na prática o que se vê é a invasão, a destruição ou o abandono dessas unidades de conservação. Entre os fatores que contribuem para que isso ocorra está a falta de fiscalização adequada por falta de recursos humanos e materiais, como aponta o estudo do Ministério do Meio Ambiente (CARVALHO, RIZZO, 1994, p.93):

Verifica-se, de uma maneira geral, que os estados litorâneos não dispõem de pessoal suficiente para efetivar o papel das unidades de conservação criadas. Neste contexto, chamam a atenção os Estados de São Paulo, Santa Catarina e Alagoas, que apresentam número insuficiente de pessoal alocado nas áreas de preservação" (grifo nosso).

Outro problema levantado no referido estudo é a ausência de plano de manejo de grande parte das Unidades de Conservação instituídas no território nacional, fato que chama a atenção, uma vez que tal estudo foi publicado em 1994 e, ainda hoje, a APA da Baleia Franca não possui plano de manejo, o que confirma o problema apontado ${ }^{6}$. A ausência de regularização fundiária é outro ponto delicado na implantação das Unidades de 
Conservação. Em se tratando da zona costeira, a questão fundiária é ainda mais complexa em razão da supervalorização imobiliária.

Este quadro de abandono das Unidades de Conservação integrantes da zona costeira apenas reforça a destruição de seus recursos naturais pela caça, pesca e extrativismo predatórios, sendo comum também a ocorrência de incêndios, desmatamentos e retiradas de plantas ornamentais.

\section{A APA E A PROTEÇÃO DA BALEIA FRANCA EM ÁGUAS JURISDICIONAIS BRASILEIRAS}

A Baleia-franca-austral (Eubalaena australis) ${ }^{7}$ também conhecida como baleiafranca ou baleia-certa ${ }^{8}$, é um dos representantes da rica fauna marinha encontrada entre os Estados do Rio Grande do Sul e Santa Catarina. Durante, aproximadamente, 400 anos se desenvolveu no Brasil-Colônia - entre os Estados da Bahia e de Santa Catarina - a caça às baleias. Segundo Jerônimo, Balod e Jerônimo (2008, p. 66) as atividades da caça à baleia foram deflagradas no sul do Estado de Santa Catarina por determinação do Marquês de Pombal, no ano de 1796. Os referidos autores asseveram, ainda, que "as grandes baleias eram arpoadas e rebocadas para os barracões, onde se organizava o retalhamento e retirava-se o toucinho para derreter em grandes calderias", os autores afirmam que o "azeite apurado como resultado final tinha dupla utilidade: era usado para iluminação pública das poucas cidades brasileiras, especialmente Rio de Janeiro e São Paulo e também era usado em fábricas de curtição

de couro" (JERÔNIMO, BALOD, JERÔNIMO, 2008, p. 66).

\footnotetext{
${ }^{6}$ O prazo de cinco anos para elaboração do plano de manejo da APA (a APA foi instituída em 2000) não foi cumprido. Em razão disso, o MPF/SC, em conjunto com a entidade da sociedade civil Coalizão Internacional da Vida Silvestre, ingressaram com Ação Civil Pública - ACP- no intuito de sanar tal omissão. Como resultado da ACP, a União e o IBAMA foram condenados a realizar o plano de manejo. Na sentença, a União foi obrigada a liberar os recursos financeiros necessários para dar início à elaboração do plano de manejo. Nesse sentido, ver: $\mathrm{ACP}^{\circ}{ }^{\circ}$ 2005.72.00.010327-9.

7 O gênero Eubalaena, segundo dados do Projeto Baleia Franca, existe desde o Pleistoceno, significando que as baleias-franca, na forma aproximada da que encontramos na costa brasileira, existem há cerca de 2,5 milhões de anos. E nos últimos 400 anos a espécie humana praticamente a levou a extinção.

8 Segundo dados disponibilizados pelo Centro de Estudos Costeiros, Limnológicos e Marinhos - CECLIMAR - da Universidade Federal do Rio Grande do Sul, as baleias-franca eram chamadas de baleia-certa, em razão de uma denominação escolhida pelos antigos baleeiros, pois considerável o animal lento, de hábitos costeiros, com uma espessa camada de gordura, consequentemente, ideal para a caça. Disponível em: http://www.ufrgs.br/ceclimar/ceram/fauna-marinha-e-costeira/baleia-franca-austral. Acesso em 10 de agosto de 2015.
} 
Destaca-se, também, que a borra do óleo da baleia era utilizada como aglutinante que petrificava a argamassa nas construções do litoral do Brasil. Conforme a pesquisa de Jerônimo, Balod e Jerônimo (2008, p. 66) a última baleia a ser morta, legalmente, no literal brasileiro, foi em 1973, no município de Imbituba, quando foi fechada a última estação baleeira no Brasil. Segundo relato do pescador responsável pela caça, o animal media 14 metros e "rendeu 40 tambores de 200 quilos cada um e que foi vendida para a Indústria Química de São Leopoldo (RS), onde transformou seu óleo em produtos diversificados”.

Até o ano de 1987, não havia, no Brasil, uma lei que regulasse a proteção dos cetáceos (baleias, golfinhos, toninhas) e a caça desenfreada e a exploração do óleo dos animais estavam os levando a completa extinção. Em 1987, no final do mês de dezembro, entrou em vigor a Lei n. ${ }^{\circ} 7.643$ e se alcança um certo grau de evolução no que concerne a proteção dos cetáceos nas águas jurisdicionais brasileiras (MEDEIROS,

2013, p. 58). A Lei n. ${ }^{\circ} 7.643 / 87$ regula a proteção em cinco (05) artigos, sendo que o dispositivo nuclear determina que "fica a proibida a pesca, ou qualquer forma de molestamento intencional, de toda espécie de cetáceo nas águas jurisdicionais brasileiras”. Mesmo não sendo uma brilhante construção normativa, segundo MEDEIROS (2013, p. 58), “de qualquer sorte, a partir da proibição de qualquer tipo de molestamento aos cetáceos na costa brasileira que foi possível o retorno das populações de várias espécies já tidas como praticamente desaparecidas de nosso litoral".

As baleias-franca, no fim do verão, deixam as áreas de alimentação, localizadas nas áreas mais frias do hemisfério sul e buscam as regiões da costa brasileira, local onde concentram-se para acasalamento, parição e amamentação dos filhotes (que nascem no ano subsequente à fecundação). Segundo os pesquisadores do Projeto Baleia Franca, estima-se que a gestação da espécie ocorra em torno dos 12 meses, que corresponderia à sazonalidade de sua migração de retorno às áreas de reprodução, onde permanecem no inverno e primavera. Em média, as fêmeas conhecidas nas áreas de reprodução têm um filhote a cada 3 anos. Não há mais nenhuma dúvida que os animais utilizam a costa brasileira como espaço de reprodução e berçário. Local de aguas calmas, quentes e de pouca profundidade. Levando isso em consideração, nos parece razoável que, depois de termos sido responsável pelo quase total desaparecimento da espécie, devamos deixa-las viver em tranquilidade.

Felipe, alicerçada nos conceitos elaborados por Paul Taylor em Respect for nature, defende que se deve tratar "do valor da vida de todos os seres a partir do bem próprio de cada vida" (FELIPE, 2014, p. 263). Taylor defende que a vida deve ser o centro da 
perspectiva ética, não fazendo diferença entre as diferentes formas de vida, pois o seu fundamento é o conceito de "bem próprio" da vida e de cada indivíduo. Afirma, ainda, que esse bem próprio não tem como medir nem comparar com o bem próprio da vida de outro indivíduo (TAYLOR, 2011). A partir desse olhar biocêntrico, para além do sensocentrismo, encontramos, com facilidade, uma justificativa ética plausível para a proteção de um espaço territorial que sirva de porto seguro às baleias- franca, pelo menos no Brasil.

Em 26 de dezembro de 1996 foi editada a Portaria IBAMA n. ${ }^{\circ}$ 117, considerando a existência de diversas espécies de cetáceos que ocorrem regularmente no interior de áreas protegidas e a necessidade de garantir sua adequada proteção contra molestamento intencional, assim como considerando o crescente desenvolvimento do turismo voltado para a observação de cetáceos em águas jurisdicionais brasileiras e a necessidade de seu ordenamento, vedou que as embarcações que operem em aguas brasileiras:

\begin{abstract}
a) aproximar-se de qualquer espécie de baleia (cetáceos da Ordem Mysticeti; cachalote, Physeter macrocephalus, e orca, Orcinus orca) com motor ligado a menos de 100m (cem metros) de distância do animal mais próximo; b) religar o motor antes de avistar claramente a (s) baleia (s) na superfície ou a uma distância de, no mínimo, de 50m (cinqüenta metros) da embarcação; c) perseguir, com motor ligado, qualquer baleia por mais de 30 (trinta) minutos, ainda que respeitadas as distâncias supra estipuladas; d) interromper o curso de deslocamento de cetáceo (s) de qualquer espécie ou tentar alterar ou dirigir esse curso; e) penetrar intencionalmente em grupos de cetáceos de qualquer espécie, dividindo-o ou dispersando-o; f) produzir ruídos excessivos, tais como música, percussão de qualquer tipo, ou outros, além daqueles gerados pela operação normal da embarcação, a menos de 300 (trezentos metros) de qualquer cetáceo; g) despejar qualquer tipo de detrito, substância ou material a menos de $500 \mathrm{~m}$ (quinhentos metros) de qualquer cetáceo, observadas as demais proibições de despejos de poluentes em Lei. (grifo nosso)
\end{abstract}

A Portaria veda, ainda, a prática de mergulho ou natação, com ou sem auxilio de equipamentos, a uma distância inferior a $50 \mathrm{~m}$ (cinquenta metros) de baleia de qualquer espécie.

Como uma das formas de estudar e proteger esses gigantescos mamíferos marinhos, nasce o Projeto Baleia Franca. O Projeto Baleia Franca foi desenvolvido pela Fundação Brasileira para a Conservação da Natureza (FBCN), que indicou uma possível recuperação da espécie Baleia Franca (Eubalaena australlis) em razão do seu aparecimento frequente na costa brasileira. A espécie, muito comum no litoral brasileiro, foi quase exterminada pela indústria baleeira, mesmo com a sua caça 
proibida desde $1931^{9}$. Conforme descreve Palazzo e Palazzo (1989, p.30), a Baleia

Franca possui as seguintes características:

\begin{abstract}
Medindo até dezesseis metros e podendo pesar quarenta toneladas, a Baleia Franca nada lentamente, frequentemente próximo das costas. Seu corpo é negro, eventualmente com manchas brancas ventrais e calosidades amareladas características no alto da cabeça. Muito dóceis e lentas, tornaram-se por isto mesmo as primeiras a serem caçadas até quase a extinção.
\end{abstract}

O projeto Baleia Franca foi apresentado à comunidade científica e conservacionista internacional em 1983, em antecedência à reunião anual da International Whaling Comission (Comissão Internacional da Baleia), em conjunto com um relatório sobre a caça à baleia. O propósito do projeto foi realizar um levantamento preliminar na costa sul do Brasil, compreendendo os Estados do Paraná, Santa Catarina e Rio Grande do Sul, com a finalidade de verificar informações sobre o reaparecimento das Baleias Francas ou Baleias Verdadeiras (Eubalaena australis) naquela área. O método adotado foi o de, utilizando um questionário específico elaborado pela $\mathrm{FBCN}$, obter informações junto aos pescadores e aos outros habitantes do litoral e, tanto quanto possível, verificar tais informações por meio de observação (PALAZZO, PALAZZO, 1989, p.31).

Vale destacar um dos trechos das entrevistas realizadas pelos pesquisadores do Projeto a um pescador da região de Garopaba (município que atualmente faz parte da APA da Baleia Franca), que relembra o caráter e o comportamento das baleias. O entrevistador relata, inclusive, que o pescador pareceu emocionado ao relembrar os fatos e descreveu as baleias como gentis e tímidas (PALAZZO, PALAZZO, 1989, p. 33):

\begin{abstract}
Ela não é perigosa. Se alguém quiser deitar sobre ela pode até dormir que ela não faz nada. O problema é que a coitada, além da perseguição dos homens ela também sofre a disputa dos peixes maiores (tubarões? Nota dos autores) que se aproveitam da sua passividade. Agora, quando ela se vê ameaçada, fica bem desajeitada e bate para tudo quanto é lado. Eu tenho um amigo que uma vez foi pescar em Armação da Piedade, quando viu uma baleia carregando o filhote no dorso ficou tão emocionado com a maneira que ela carregava que acabou desistindo da pesca e nunca mais quis voltar a pescar baleia.
\end{abstract}

\footnotetext{
9 A Convenção para a Regulamentação da Caça à Baleia, de 1931, da qual o Brasil foi signatário, entrou em vigor em 16 de janeiro de 1935, em seguimento à sua ratificação por 48 nações signatárias. A Convenção proibiu a captura e a matança de qualquer baleia, tanto a Baleia Franca quanto as de outras espécies. As partes signatárias concordaram em fiscalizar as determinações da Convenção e aplicá-las a todos os mares, incluindo águas internacionais e nacionais (PALAZZO, PALAZZO, 1989, p.36).
} 
Com os dados coletados com ajuda dos questionários propostos e pelas observações in loco, o projeto propôs ao governo medidas para a proteção específica das áreas costeiras em que ficasse comprovada a concentração de Baleias Franca, a fim de garantir que o Brasil cumpra com as suas obrigações contraídas em acordos internacionais, objetivando possibilitar às baleias a recuperação de suas populações a níveis seguros para permitir a cientistas brasileiros e de outras nações a oportunidade de observar essas baleias em uma área de defesa à caça; e para considerar, eventualmente, os potencias turísticos para observação de baleias sem molestá-las ${ }^{10}$ (PALAZZO, PALAZZO, 1989, p.34).

Assim, o Projeto Baleia Franca acabou influenciando diretamente a criação da APA da Baleia Franca. É claro que a APA não visa apenas à proteção das Baleias Francas. Esse foi apenas o mote utilizado para criação da área de preservação ambiental ${ }^{11}$.

Importante salientar que a APA da Baleia Franca nasceu com um viés conservacionista, pois sua criação deu-se por influência do Projeto Baleia Franca. O estabelecimento da APA não foi uma reivindicação das comunidades locais (ALBUQUERQUE, 2009, p.112).

A Área de Proteção Ambiental da Baleia Franca, foi, portanto, instituída pelo Decreto $\mathrm{s} / \mathrm{n}^{\circ}$ de 14 de setembro de $2000^{12}$, tendo como finalidade, conforme disposto no artigo $1^{\circ}$ do Decreto de 14/09/2000:

proteger, em águas brasileiras, a Baleia Franca Austral, Eubalaena australis, ordenar e garantir o uso racional dos recursos naturais da região, ordenar a ocupação e a utilização do solo e das águas, ordenar o uso turístico e recreativo, as atividades de pesquisa e o tráfego local de embarcações e aeronaves.

\footnotetext{
10 Vale registrar que atualmente, mesmo após a instituição da APA, a observação de baleias, um dos atrativos turísticos da região, não é realizada da maneira ambientalmente correta, ou seja, de forma a respeitar os cetáceos sem molestá-los. Verifiquei in loco, em visita à Praia do Rosa, grupos de turistas aproximando-se com caiaques de uma baleia acompanhada do filhote. Na ocasião, eu estava em terra com um grupo de biólogos que desenvolvem pesquisas na região e que confirmaram que este tipo de aproximação incomoda os animais. Além disso, os biólogos relataram que uma determinada pousada da região, que vende pacotes turísticos para observação de baleias, faz a cooptação de biólogos (estudantes de biologia) junto a ONGs para acompanhar estes grupos de turistas, oferecendo em contrapartida hospedagem durante o período das pesquisas dos biólogos. No entanto, os proprietários da pousada acabam tratando os biólogos como empregados do estabelecimento e como guias disponíveis para acompanhar os turistas a qualquer hora do dia na observação das baleias, nem sempre respeitando os parâmetros de segurança no sentido de não prejudicar nem molestar as baleias e seus filhotes.

${ }^{11}$ Um dos idealizadores do Projeto Baleia Franca foi o Vice-Almirante Ibsen Gusmão Câmara, da Marinha do Brasil, presidente da FBCN na época de sua realização.

12 Disponível em: < http://br.geocities.com/apadabaleiafranca/leis.html >. Acesso em 10 de março de 2007.
} 
Situada no litoral sul de Santa Catarina, a APA da Baleia Franca abrange uma grande área terrestre e aquática, incluindo nove municípios da região, em uma área total de mais de 150 mil hectares. Essa Unidade de Conservação seria uma parceira importante para qualquer iniciativa de gestão participativa ou de criação de outras Unidades de Conservação em seu interior que possam beneficiar as populações locais em razão da sua abrangência ao redor das Lagoas do Camacho, Garopaba do Sul e Santa Marta, bem como pelo seu potencial de regulamentação de atividades potencialmente degradadoras do ambiente (ALBUQUERQUE, 2009, p. 112). Haja vista a APA enfrenta muitos outros "desafios ambientais" do que a proteção das baleias, como a mineração no interior das lagoas da região, a pesca predatória e expansão imobiliária.

A APA da Baleia Franca possui um elevado grau de ocupação humana, não somente em razão da sua extensão geográfica, mas também por sua localização na zona costeira. Sua área abrange 156.100 hectares, com aproximadamente 130 quilômetros de extensão. A APA estende-se desde a Ponta Sul da Praia da Lagoinha do Leste, na Ilha de Santa Catarina, até o Balneário do Rincão, ao sul do Cabo de Santa Marta, abrangendo 9 municípios: Florianópolis, Palhoça, Paulo Lopes, Garopaba, Imbituba, Laguna, Tubarão, Jaguaruna e Içara. Verifica-se um elevado grau de ocupação humana na zona costeira, fato justificado historicamente, pois a ocupação de todas as áreas coloniais no continente americano iniciou-se por via marítima, sendo as zonas litorâneas as primeiras a conhecerem núcleos de povoamento. O Brasil, segundo Moraes (2007), seguiu esse padrão de assentamento colonial de tal forma que, atualmente, a densidade demográfica da zona costeira, de 87 habitantes por quilômetro quadrado, é cinco vezes superior à média nacional, que é de 17 habitantes por quilômetro quadrado.

Essa concentração demográfica também pode ser observada na diversidade e na convivência de padrões díspares: podemos encontrar na costa brasileira tribos coletoras isoladas, plantas industriais de última geração, comunidades tradicionais e grandes metrópoles. Tais características podem redundar em um alto potencial de conflituosidade pelo uso e ocupação do solo (MORAES, 2007, p.31-32). No que diz respeito à APA da Baleia Franca, esse potencial de conflituosidade, referido por Moraes, pode ser identificado em diversos casos. 
O Decreto de criação da APABF tenta diminuir esse espaço de potencial conflito já determinando quais as atividades que ficam sujeitas à regulamentação dos órgãos competentes. Dentre elas, destaca-se a exploração de serviços turísticos voltados à observação das baleias franca e demais espécie de cetáceos, bem como acesso ás ilhas públicas englobadas em seu perímetro. Em 2000, quando da publicação do Decreto, a responsabilidade de administração da APABF era do Instituto Brasileiro do Meio Ambiente e dos Recursos Naturais Renováveis - IBAMA, no entanto, com a criação, em 2007, de uma nova autarquia ambiental em regime especial, o Instituto Chico Mendes de Conservação da Biodiversidade - ICMBio - a administração da APA passou a ser deste e não mais daquele.

No ano de 2006, foi publicada a Instrução Normativa . $^{\circ} 102$, de 19 de julho (IN N. 102 IBAMA) com o intuito de estabelecer restrições às atividades náuticas específicas em setores da APABF durante os meses de junho a novembro. De acordo com o artigo $2^{\circ}$, da IN n. 102 IBAMA:

Art. $2^{\circ}$ Nestes setores ficam vedadas as seguintes atividades náuticas por embarcações motorizadas:

I - o transporte de passageiros com finalidade turística, mediante pagamento ou não;

II - a prática e apoio a qualquer forma de esporte náutico; e, III - atividades recreativas em geral. (grifo nosso)

As áreas sujeitas a estas restrições são: a Praia da Vila (Imbituba/SC); a Praia d’Água (Imbituba/SC); a Praia da Gamboa (Garopaba/SC); a Praia do Luz (IbiraqueraImbituba/SC); e, a Praia do Silveira (Garopaba/SC). Na Praia de Garopaba fica assegurado o direito de acesso a embarcações, com a finalidade única de promover o embarque e desembarque de passageiros. Contudo, mesmo com as medidas restritivas, a APABF vem sofrendo por não cumprir com os desígnios com e para os quais foi criada. Em face disso, pela inércia dos órgãos públicos, a sociedade civil organizada foi em busca da proteção judicial, através da atuação do Poder Judiciário.

\section{A JUDICIALIZAÇÃO DA PROTEÇÃO DAS BALEIAS}

Em 07 de novembro de 2012 o Instituto Sea Shepherd Brasil (ISSB) ajuizou Ação Civil pública contra o Instituto Chico Mendes de Conservação da Biodiversidade (ICMBio) objetivando que o ICMBio seja condenado a adotar, de forma permanente, 
as medidas necessárias e eficazes para a proteção das baleias, inclusive mediante fiscalização das empresas que praticam a observação de baleias com uso de embarcações, com ou sem motor, a fim de impedir a violação da legislação, sob pena de multa no valor de $\mathrm{R} \$ 500.000,00$ (quinhentos mil reais).

O ISSB postulou, a título de antecipação de tutela, dentre outros pedidos, a suspensão da prática de observação de baleias com o uso de embarcações, com ou sem motor, dentro dos limites e zona de amortecimento da $\mathrm{APABF}$, até que o ICMBio comprove nos autos as medidas administrativas adotadas para que a legislação pertinente seja cumprida pelas empresas, condicionadas à análise e verificação prévias do Ministério Público Federal e do próprio ISSB.

A Justiça Federal decidiu, liminarmente, inaudita altera parte, que o ICMBio:

a) Fiscalize imediatamente a atividade de observação de baleias com uso de embarcações nos limites e zona de amortecimento da APA da Baleia Franca, bem como adote medidas que coíbam o descumprimento das limitações e distancias mínimas previstas na legislação, em especial na Portaria 117/1996 e na Instrução Normativa 102/2006 ambas do IBAMA;

b) Comprove a realização da fiscalização em todas as embarcações que realizam a observação de baleias nos limites e zona de amortecimento da APA da Baleia Franca, anexando aos autos a respectiva vistoria.

No mesmo ato decisório a Juíza Federal encarregada decidiu que o ICMBio deveria anexar aos autos cópias das autuações efetivadas nos últimos três anos, de embarcações que violaram a legislação de proteção aos cetáceos na área da APABF e sua zona de amortecimento. Exigiu a apresentação do rol de embarcações e empresas cadastradas que operam regulamente na Unidade de Conservação. Exigiu a informação do número máximo de embarcações cuja operação simultânea é permitida no interior da Unidade de Conservação, bem como as rotas e velocidades para transito de tais embarcações no interior e/ou na proximidade das áreas de concentração ou de uso regular por cetáceos. E exigiu, ainda, que o ICMBio informasse as mortes dos cetáceos ocorridas nos últimos três anos no interior da Unidade de Conservação, de que se tenha registro, em decorrência do choque com embarcações que realizavam a observação de baleias, com a apresentação do respectivo laudo de necropsia.

A juíza federal competente, nesse primeiro momento, entendeu existir fumus boni Iuri e periculum in mora e concedeu a antecipação de tutela requerida pelo autor (evento 3), haja vista, as provas acostadas nos autos, apontavam para a verossimilhança das alegações, pois até mesmo uma foto de divulgação do turismo de observação apresentava turistas 
com os pés apoiados no dorso de uma baleia. Para além da desobediência à legislação, há nesse ato um risco claro contra o animal não humano e um risco claro contra o animal humano, pois apesar de ser um animal calmo, não violento e lento, um filhote já pesa mais de 16 toneladas, podendo causar um acidente significativo, no caso da embarcação com motor desligado.

Em um segundo momento, o autor, o ISSB, requereu a inclusão na lide das três empresas que atuam na área de turismo de observação de baleias embarcado, na região, pedido esse que foi negado. Contudo, destaca-se que o Estado de Santa Catarina e a empresa Turismo, Vida, Sol e Mar LTDA. Me. foram, posteriormente, integradas a lide como assistentes litisconsorciais passivos.

Em decisão do evento 25 do processo judicial eletrônico, entendendo restar demonstrada a verossimilhança das alegações do ISSB e a relevância dos argumentos expendidos pelo autor, assim como o perigo de dano irreparável ou de difícil reparação na hipótese de continuidade da atividade, o juízo determinou:

a) a suspensão imediata da observação de baleias -francas com o uso de embarcações, com ou sem motor, nos limites e zona de amortecimento da APA da Baleia Franca nos Município de Garopaba, Imbituba e Laguna, até que haja estudo acerca da viabilidade ambiental da atividade na região, bem como licenciamento ambiental da atividade;

b) que o ICMBio se abstenha de expedir quaisquer atos para autorizar o exercício da atividade de observação de baleias-francas com uso de embarcações nos limites e zona de amortecimento da APA da Baleia Franca nos Município de Garopaba, Imbituba e Laguna;

c) na hipótese de o edital referente ao ano de 2013 já ter sido expedido ou as empresas já estarem cadastradas, que o ICMBio suspenda imediatamente o cadastramento ou as autorizações, comprovando tais medidas nos autos no prazo de 15 dias; e

d) que o ICMBio adote medidas administrativas cabíveis para fiscalizar e coibir a atividade de observação de baleias-francas com uso de embarcações nos limites e zona de amortecimento da APA da Baleia Franca nos Município de Garopaba, Imbituba e Laguna, enquanto não finalizado o estudo acerca da viabilidade ambiental da atividade na região e o respectivo licenciamento ambiental.

Inconformado com a manutenção da decisão antecipatória, o ICMBio interpõe um Agravo de Instrumento junto ao TRF $-4^{\text {a }}$ Região, com o intuito de ver reformada a decisão de primeiro grau. Trata-se, portanto, de interposição de agravo de instrumento, com pedido de efeito suspensivo, interposto contra a decisão que suspendeu o turismo de observação de baleias na APABF.

O ICMBio alega que o ato é respaldado em estudos da comunidade científica, que atestam que a aproximação às embarcações é o comportamento regular das baleias e ocorre 
em todos os locais do mundo em que tal atividade é exercida. Refere, ainda, que a regulamentação e o monitoramento adotados pela APA são suficientes para serem entendidos como um licenciamento ambiental e fazerem as vezes de fiscalização, sendo desproporcional que tal fiscalização acompanhe, individualmente, todas as embarcações. O ICMBio sustenta que a APA da Baleia Franca tem uma importante função de educação ambiental, objetivando sustentabilidade com justiça ambiental.

Ora, antes mesmo de analisarmos a decisão do TRF4, urge questionar os argumentos de educação ambiental e sustentabilidade com o objetivo de alcançar a justiça ambiental. Que tipo de educação é essa que ensina a não cumprir as determinações legais? Que tipo de sustentabilidade é essa que só leva em consideração o desenvolvimento econômico da atividade e não a finalidade para a qual a Unidade de Conservação foi criada?

Do ponto de vista da sustentabilidade podemos defender, aqui, pelo menos quatro dimensões a serem respeitadas: ética; social; econômica; e, ambiental. Não é possível verificar a sustentabilidade de uma atividade analisando apenas o viés econômico. A partir de uma dimensão ética da sustentabilidade, se parte do "sentido de que todos os seres possuem uma ligação intersubjetiva e natural, donde segue a empática solidariedade como dever-prazer universalizável (...)" (FREITAS, 2011, p.

57). O autor ressalta, ainda, que "o importante é que o outro, no seu devido apreço, jamais seja coisificável". Freitas assevera que "há dever ético de sustentabilidade ativa, que esclarece, não manipula, nem instrumentaliza. Existe dever ético de ser benéfico para todos os seres, no limite do possível, não apenas deixar de prejudica-los” (2011, p. 58).

No âmbito da dimensão ambiental da sustentabilidade, Freitas (2011) defende que existe uma dignidade do ambiente, assim como se reconhece o direito das gerações atuais, sem prejuízo das futuras, ao ambiente limpo, em todos os aspectos. O autor defende que (FREITAS, 2011, p. 61):

Não faz sentido persistir nessa matriz comportamental da destruição ilimitada e do poder neurótico sobre a natureza, não somente porque os recursos são finitos, mas porque tal despautério faz milhões de vítimas no caminho. 
Ainda nesse sentido, advogam Sarlet e Fensterseifer (2014, p. 93) ao afirmar que:

O princípio do desenvolvimento sustentável expresso no art. 170 (inciso VI) da $\mathrm{CF} / 88$, confrontado com o direito de propriedade privada e a livre-iniciativa (caput e inciso II do art. 170), também se presta a desmistificar a perspectiva de um capitalismo liberal-individualista em favor dos valores e princípios constitucionais ambientais. Com relação à pedra estruturante do sistema capitalista, ou seja, a propriedade privada, os interesses do seu titular devem ajustarse aos interesses da sociedade e do Estado, na esteira das funções sociais e ecológicas que lhe são inerentes.

No que concerne a atividade econômica de turismo de observação de baleias embarcado, há a necessária ponderação entre economia e ambiente, para determinar o mínimo. Não é possível autorizar o exercício de uma atividade econômica se esta colocará em risco o equilíbrio do ecossistema em que estará se inserindo. A velocidade do desenvolvimento científico, ou mesmo da forma como o mundo, hoje, se organiza, seja economicamente ou socialmente, força que se dê uma parada, se freie algumas posturas, para que, no futuro, ainda tenhamos algum ambiente com o qual nos preocupar.

No evento 4, da decisão do Agravo de Instrumento, pelo TRF4, temos as seguintes considerações, a partir da leitura do Desembargador Relator, entendendo haver sido comprovada a fumaça do bom direito e o perigo da demora, dispondo que (evento4, p. 4):

Colhe-se das alegações apresentadas na contestação e dos documentos trazidos aos autos pelo autor e pelo ICMBio que inexis te qualquer estudo sobre o impacto ambiental da observação de baleias-francas com uso de embarcacões nos limites e zona de amortecimento da APA da Baleia Franca, de modo que a atividade é realizada sem o conhecimento dos eventuais riscos e malefícios que possa causar às baleias-francas.

Nestes termos, o ICMBio autoriza, as empresas exploram e o público participa de tal atividade desconhecendo as consequências que possa causar às baleias-francas, o que, com base no princípio da precaução, é suficiente para justificar a suspensão da observação de baleias -francas com uso de embarcações limites e zona de amortecimento da APA da Baleia Franc a nos Município de Garopaba, Imbituba e Laguna, até que tais estudos sejam realizados e a eventual viabilidade da atividade seja verificada.

E mais, o relator defende, em posicionamento idêntico ao dessa pesquisa, que

(evento 4, p. 4):

Por certo, a aplicação da legislação protetiva dos cetáceos e a fiscalização e monitoramento realizados pelo ICMBio não estão sendo suficientes para garantir a segurança de baleias-francas, turistas e embarcações envolvidos na atividade, até mesmo em razão das características do litoral em que é realizada e de fatores como a movimentação das marés, os ventos e o próprio deslocamento das baleias-francas. Tais fatores acabam por colocar em risco não só as baleias -francas, como também turistas e exploradores da atividade (grifo nosso). 
Dessa feita, o TRF4, acompanhando a decisão de primeiro grau, determina a suspensão da atividade do turismo de observação de baleia embarcado (evento 4, p. 5):

\begin{abstract}
Assim sendo, e ante o perigo de que a observação de baleias com uso de embarcações nos limites e zona de amortecimento da APA da Baleia Franca continue sendo realizado enquanto não conhecido seu impacto ambiental, entendo prudente determinar, antecipadamente, a suspensão imediata da observação de baleias-francas com o uso de embarcações, com ou sem motor, nos limites e zona de amortecimento da APA da Baleia Franca nos Município de Garopaba, Imbituba e Laguna, até que haja estudo acerca da viabilidade ambiental da atividade na região, bem como licenciamento ambiental da atividade. (grifo nosso).
\end{abstract}

Sarlet e Fensterseifer (2014, p. 94) defendem a ideia de que a ordem econômica disciplinada pela Constituição Federal teria adotada uma opção "pelo que se poderia designar de um capitalismo ambiental ou socioambiental (...) capaz de compatibilizar a livre iniciativa, a autonomia e a propriedade privada com a proteção ambiental e a justiça social”. E, ainda, destacam que

\begin{abstract}
Para ilustrar esse projeto normativo em termos práticos, destaca-se, dentre outros instrumentos jurídicos criados com o propósito de conciliar as práticas produtivas com a proteção ambiental, o estudo prévio de impacto ambiental (art. 225, § $1^{\circ}$, IV, da CF/88, art. 10 da Lei n. ${ }^{\circ}$ 6.938/81 e Resolução 237/97 do CONAMA) exigido para a instalação de obra ou atividade causadora ou potencialmente causadora de significativa degradação ambiental (SARLET; FENSTERSEIFER, 2014, p. 94).
\end{abstract}

Dessa feita, em face da total existência de estudo prévio de impacto ambiental para se atestar a viabilidade, ou não, da atividade econômica, não há como se admitir a liberação, haja vista o princípio da precaução ser um corolário do Direito Ambiental e o estudo prévio de impacto ambiental uma exigência constitucional. A tarefa do princípio da precaução é proteger "porque desconhece o risco de determinada atividade humana, ou mesmo se existe o risco da referida atividade ou empreendimento em razão da falta de estudos científicos conclusivos suficientes" (MEDEIROS; ROCHA, 2015, p. 43). Na mesma linha, Sarlet e Fensterseifer defendem que "o princípio da precaução, como uma espécie de princípio da prevenção qualificado ou mais desenvolvido, abre caminho para uma nova racionalidade jurídica" (2014, p. 164). Os autores asseveram que, em linhas gerais, "diante da dúvida e da incerteza científica a respeito da segurança e das consequências do uso de determinada substancia ou tecnologia, o operador jurídico deve ter como fio condutor uma postura precavida" (SARLET; FENSTERSEIFER, 2014, p. 164). 
Com a manutenção da decisão de primeiro grau, pelo TRF4, tem-se o atual estado da arte com a suspensão da atividade econômica do turismo de observação de baleia embarcado - TOBE, aguardando a possibilidade de uma audiência de conciliação nos autos do processo.

\section{CONCLUSÃO}

Hodiernamente, o direito tem se mostrado aberto a enfrentar algumas discussões até então inimagináveis. Há sinais indubitáveis que a ética antropocêntrica está sendo ultrapassada, talvez não a passos largos, mas com certeza os passos são avante. O presente artigo partiu da análise do enfrentamento da proteção jurídica de animais não humanos - a baleia franca - e o exercício de uma atividade econômica aparentemente conservacionista e sustentável.

O estudo partiu de uma análise de fontes bibliográficas, normativas e de um estudo de caso, a partir de um processo judicial - uma ação civil pública - que ainda está em andamento. Para tanto, foi analisado o Sistema Nacional de Unidades de Conservação, regulado pela Lei 9985/2000, que estabelece duas grandes categorias de Unidades de Conservação: as unidades de conservação de proteção integral e as unidades de conservação de uso sustentável. Entre as unidades de conservação de uso sustentável, as áreas de proteção ambiental caracterizam-se por serem áreas extensas, instituídas para a preservação dos processos naturais e da biodiversidade, bem como para regular as atividades humanas às características ambientais da área.

Assim, no sul do estado de Santa Catarina foi instituída a Área de Proteção Ambiental da Baleia Franca (APABF), com o objetivo principal de proteger nas aguas brasileiras a baleia franca austral. Recentemente, a APABF está sendo palco de um intenso conflito socioambiental em razão da Ação Civil Pública (ACP) interposta pelo Instituto Sea Shepherd Brasil em face do Instituto Chico Mendes da Biodiversidade (ICMBIO), pedindo a condenação do ICMBIO a adotar de forma permanente, as medidas necessárias e eficazes para a proteção das baleias-francas, mediante a fiscalização das empresas que praticam a observação das baleias com uso de embarcações, com ou sem motor, a fim de impedir a violação da legislação. Este artigo consiste em um estudo de caso e visa contribuir para o conhecimento do caso do turismo de observação de baleias embarcado na APABF, 
através da análise da legislação aplicada, como dos atores envolvidos na controvérsia judicial e o seu reflexo para os direitos animais.

A proteção jurídica dos animais não humanos, no Brasil, é norma constitucional, assim como a exigência de estudo de impacto ambiental para atividades de potencial poder ofensivo ao ambiente. No objeto analisado, constata-se a ausência, por parte do ICMBio de um cuidado para com os animais não humanos assim como uma desatenção aos preceitos econômicos ambientais regulados pela constituição.

Em termos de uma leitura e reflexão ainda preliminar da pesquisa, haja vista o processo ainda estar em andamento, se pode concluir, com certa tranquilidade, que a atividade de turismo de observação de baleia embarcada - TOBE - se apresenta mais como uma atividade insustentável do que o contrário, se apresenta muito mais como uma atividade exploradora dos animais não humanos do que educadora ambiental. Educação ambiental, justiça ambiental e sustentabilidade se concretiza com o aumento do número de indivíduos da espécie no litoral brasileiro, com o respeito para com os animais não humanos e consequentemente com o respeito para com os animais humanos das gerações presentes e das futuras gerações.

\section{REFERÊNCIAS BIBLIOGRÁFICAS}

ALBUQUERQUE, Leticia. Conflitos socioambientais na zona costeira catarinense. Tese. Florianópolis: UFSC, 2009.

BRASIL. Constituição da República Federativa do Brasil de 1988. Disponível em: http://www.planalto.gov.br/ccivil_03/Constituicao/ConstituicaoCompilado.htm

BRASIL. JUSTIÇA FEDERAL. AÇÃO CIVIL PÚBLICA N. ${ }^{\circ}$ 500223648.2012.404.7216/SC.

BRASIL. Lei n. ${ }^{\circ}$ 7.643, de 18 dezembro de 1987. Disponível em: http://www.planalto.gov.br/ccivil_03/Leis/L7643.htm

BRASIL. Lei n. ${ }^{\circ}$ 9.985, de 18 de julho de 2000. Disponível em: http://www.planalto.gov.br/CCivil_03/leis/L9985.htm

BRASIL. TRF4. AGRAVO DE INSTRUMENTO N. ${ }^{\circ}$ 5012653-43.2013.404.0000/SC CABRAL, Najila Rejane Alencar Julião. SOUZA, Marcelo Pereira. Área de Proteção Ambiental: planejamento e gestão de paisagens protegidas. São Carlos: RIMA, 2005. 
CARVALHO, Vitor. RIZZO, Hidelly. A Zona Costeira Brasileira: subsídios para uma avaliação ambiental. Brasília: MMA, 1994.

FELIPE, Sônia T. Acertos abolicionistas - a vez dos animais. São José (SC): Ecoânima, 2014.

FREITAS, Juarez. Sustentabilidade: direito ao futuro. Belo Horizonte: Editora Fórum, 2011.

JERÔNIMO, Daniel; B ALOD, Edison P.; JERÔNIMO, Rosa N. T. História, ambiente e turismo: da caça à preservação da Baleia Franca em Garopaba e Imbituba - SC. Gaia Scientia. 2008, 2 (1): p. $63-$ p. $74 . \quad$ Disponível em: http://www.okara.ufpb.br/ojs/index.php/gaia/article/viewFile/2548/2221. Acesso em $10 \mathrm{de}$ julho de 2015.

MACHADO, Paulo Affonso Leme. Direito Ambiental Brasileiro. São Paulo: Malheiros, 2012.

MEDEIROS, Fernanda Luiza Fontoura de. Direito dos Animais. Porto Alegre: Livraria do Advogado, 2013.

MEDEIROS, Fernanda Luiza Fontoura de. Meio Ambiente: direito e dever fundamental. Porto Alegre: Livraria do Advogado, 2004.

MEDEIROS, Fernanda Luiza Fontoura de; ROCHA, Marcelo Hugo da. Como se preparar para o Exame da Ordem. Vol. 11. Ambiental. Rio de Janeiro: Forense, 2015.

MILANO, Miguel. Conceitos básicos e princípios gerias de planejamento, manejo e administração. In: Encontro de Planejamento de Unidades de Conservação, 1999. Santa Teresa: UFES, 1999.

MORAES, Antonio Robert Moraes. Contribuições para a gestão da zona costeira do Brasil: elementos para uma geografia do litoral brasileiro. São Paulo: Annablume, 2007.

PALAZZO, Miriam. PALAZZO, José Truda. S.O.S. Baleia!: a história do maior movimento conservacionista de todos os tempos. Porto Alegre: Sulina, 1989.

PROJETO BALEIA FRANCA. $\underline{\text { www.baleiafranca.org.br }}$

SARLET, Ingo Wolfgang; FENSTERSEIFER, Tiago. Princípios do Direito Ambiental. São Paulo: Saraiva, 2014.

SILVA, José Afonso da. Direito Ambiental Constitucional. São Paulo: Malheiros, 2007.

TAYLOR, Paul W. Respect for nature: a theory of environmental ethics. Princeton: Princeton University Press, 2011. 